\title{
CELL CYCLE PROGRESSION IS ASSOCIATED WITH DISTINCT PATTERNS OF PHOSPHORYLATION OF OP18
}

\author{
John R. Strahler*, Barbara J. Lamb*, David R. Ungar*, David A. Fox ${ }^{\S}$ and Samir M. Hanash* \\ University of Michigan Medical School, Departments of *Pediatrics and \$Internal Medicine, Ann \\ Arbor, MI, 48109
}

Received April 15, 1992

Op18 is a highly conserved major cytosolic phosphoprotein which has been implicated in signal transduction in a wide variety of cell types. Freshly isolated peripheral blood lymphocytes (PBL) constitutively express low levels of mostly unphosphorylated Op18. Following mitogenic stimulation of PBL, Op18 synthesis is induced at a time when cells are entering S-phase. In this study we have characterized Op18 phosphorylation during progression of freshly isolated PBL through the cell cycle. Transition from G0 to G1 following activation with OKT3 was associated with an increase in a phosphorylated form designated Op18c. Progression of cells through G1 into $S$ resulted in an increase in phosphorylated Op18 forms, designated Op18a and Op 18b, which paralleled new Op18 synthesis. Transition of cells into G2+M resulted in the appearance of the more acidic phosphorylated forms Op18d and Op18e. Calphostin C, a specific inhibitor of protein kinase C, dramatically decreased all forms of phosphorylated Op18 in OKT3 treated Jurkat cells. Our results suggest that Op18 phosphorylation is mediated in part by PKC activation as well as by other kinases yielding different phosphorylated forms at specific stages of the cell cycle. $\$ 1992$ Acadernic Press, Inc.

Op18 is a proliferation related protein which in PBL is induced in late G1 following mitogenic stimulation (1-3) and which is overexpressed in acute leukemia and some solid tumors (1). We have cloned and sequenced two cDNAs for Op18 which code for the same 149 amino acid polypeptide (4). Disruption of Op18 mRNA translation with antisense oligonucleotides resulted in delayed entrance of PBL into S phase (5). Conversely, induction to terminal differentiation of K562 erythroleukemia cell line with hemin (5) and of HL-60 promyelocytic leukemia cell line with DMSO or PMA (2) resulted in down-regulation of Op18 levels.

Comparison of the human cDNA coding sequence for Op18 with sequences published to date has revealed that Op18 is identical to a cytosolic polypeptide observed in different species and designated by by others as stathmin (6), p19 (7) and 19K (8) and that Op18 exhibits a high degree of conservation in its amino acid sequence. Also, from its pI and MW on 2-D gels, Op18 is highly likely identical to prosolin (3) and pp21/pp23 (9) described in proliferating PBL and T cell lines.

Op18 undergoes phosphorylation in a wide variety of proliferating cells (10). Its phosphorylation has been implicated in signal transduction in rat brain (11) and PC12 cells (6). In quiescent PBL, Op18 is present at low levels. However two phosphorylated forms can be detected by metabolic labeling with ${ }^{32} \mathrm{P}_{\mathrm{i}}(12)$. Additional phosphorylated forms have been observed in 
proliferating $T$ cells by ourselves (12) and others $(3,13,14)$ following mitogenic stimulation. We have identified as many as seven phosphorylated forms of Op18 in PMA activated Jurkat cells by Western blotting (12). Two phosphorylated forms with an apparent mass of $17.3 \mathrm{kD}$ designated Op18a and b have pI 5.80 and 5.61, respectively, compared to pI 6.0 of unphosphorylated 17.3 $\mathrm{kD}$ Op18. Op18c is an $18.1 \mathrm{kD}$ form with $\mathrm{pI}$ similar to Op18b. Op18d is more acidic (pI 5.42) and has greater apparent mass $(18.8 \mathrm{kD})$. Three minor $17.3 \mathrm{kD}$ forms have pIs $5.66,5.48$ and 5.40. We have recently described protein kinase $\mathrm{C}$ mediated phosphorylation of Op18 giving rise to the form designated Op18c as early as $2 \mathrm{~min}$ following $\mathrm{T}$ cell activation (12).

In this study we have characterized Op18 phosphorylation in freshly isolated PBL during cell cycle progression. Our results indicate a different pattern of phosphorylation related changes in Op18, at differnt stages of the cell cycle.

\section{METHODS}

Peripheral blood lymphocyte preparation and cell synchronization: Human PBL were prepared from venous blood of healthy volunteers. Whole mononuclear cells were isolated from heparanized blood by centrifugation ( $1500 \mathrm{x} \mathrm{g}, 15 \mathrm{~min}$, room temperature) over Ficoll-Paque (Pharmacia) and cultured in RPMI 1640 supplemented with $10 \%$ fetal calf serum. PBL were mitogenically stimulated with anti-CD3 (OKT3 ascites, 1:200). To achieve synchronization, 10 $\mathrm{mM}$ hydroxyurea was added $24 \mathrm{~h}$ following OKT3 stimulation and PBL were cultured for an additional $20 \mathrm{~h}$ to allow cells to accumulate in S phase. Cells were washed three times with media and returned to the original flask with fresh OKT3 added. Three $\mathrm{h}$ following release of the block in S phase, $100 \mathrm{ng} / \mathrm{ml}$ nocodazole was added for $21 \mathrm{~h}$ to block cells in $\mathrm{M}$. The leukemia T cell line Jurkat was maintained in supplemented RPMI 1640 at a density of $0.5-1 \times 10^{6} / \mathrm{ml}$.

Cell cycle analysis: The percentage of cells in G0/G1, S and G2+M was determined by DNA staining with propidium iodide (15). Cells were fixed in $70 \%$ ethanol and incubated overnight at $4^{\circ} \mathrm{C}$. Cells were resuspended in MEM containing $2 \%$ newborn calf serum, $500 \mathrm{U} / \mathrm{ml}$ RNase A and $0.1 \%$ sodium azide and incubated at $37^{\circ} \mathrm{C}$ for $1 \mathrm{~h}$. An equal volume of $50 \mu \mathrm{g} / \mathrm{ml}$ propidium iodide in $1.12 \%$ sodium citrate, $\mathrm{pH} 8.4$ was added and cells were incubated at room temperature for $30 \mathrm{~min}$. The samples were analyzed on a FACScan (Becton Dickinson). DNA content was determined by rectangular modeling using the CellFIT software program.

[ $\left.{ }^{32} \mathrm{P}\right]$ incorporation: Non-adherent cells $\left(2.5 \times 10^{6}\right.$ cells $)$ were washed once with phosphatefree RPMI 1640 and resuspended in $300 \mu l$ phosphate-free medium containing $\left[{ }^{32} \mathrm{P}\right]$ orthophosphate $(450 \mu \mathrm{Ci} / \mathrm{ml}$, carrier free; Amersham), in $1.5 \mathrm{ml} \mathrm{microcentrifuge} \mathrm{tubes.} \mathrm{Incubation}$ at $37^{\circ} \mathrm{C}$ was for 60 to $90 \mathrm{~min}$. For inhibition studies using the specific protein kinase $\mathrm{C}$ (PKC) inhibitor calphostin $\mathrm{C}$ (Kamiya Biochemical) the working stock solution was activated by exposure to fluorescent light for $15 \mathrm{~min}$ prior to addition to cells (16).

Two dimensional polyacrylamide gel electrophoresis (2-D PAGE): Two-dimensional PAGE using carrier ampholyte-based isoelectric focusing was performed as previously described (17) using pH 4-8 Resolyte (2\% w/v; Hoefer Scientific). Whole cell lysates were prepared ( $2.5 \mathrm{x}$ $10^{6}$ cells) with $30 \mu \mathrm{l}$ lysis solution $(9.5 \mathrm{M}$ urea, $2 \%$ 2-mercaptoethanol, $2 \%$ Nonidet-P40, containing $50 \mathrm{mM} \mathrm{NaF}$ and $0.1 \mathrm{mM}$ Na vanadate as phosphatase inhibitors). The lysate was centrifuged for $2 \mathrm{~min}$ and $2.5 \times 10^{6}$ cell equivalents were applied to the isofocusing gel. Focusing was for $16 \mathrm{~h}$ at $1000 \mathrm{~V}$. The second dimension separation was an 11.4 to $15 \%$ acrylamide gradient SDS gel. Following the second dimension separation, proteins were fixed in the gel with $50 \%$ ethanol and 5\% acetic acid. Gels were washed for $15 \mathrm{~min}$ with $2 \%$ glycerol and $30 \%$ ethanol and dried. Phosphorylated polypeptide 2-D images were obtained using a PhosphorImager System (Molecular Dynamics) (18). Exposure time was 41 to $72 \mathrm{~h}$. 


\section{RESULTS}

Cell cycle analysis of PBL: To determine whether Op18 phosphorylation is modulated during transition of cells through the cell cycle, PBL were synchronized with a combination of hydroxyurea and nocodazole. PBL were stimulated through the $\mathrm{T}$ cell receptor with anti-CD3 (OKT3) for $24 \mathrm{~h}$ and subsequently treated with hydroxyurea, which inhibits ribonucleoside diphosphate reductase, and nocodazole, a microtubule-depolymerizing drug, to modulate transit through the cell cycle. The DNA content histogram is shown in Figure 1. DNA content of cells was determined by FACS analysis. By $47 \mathrm{~h}, 24 \%$ of the cells entered the cell cycle (S+G2+M). Following $24 \mathrm{~h}$ of OKT3 treatment the majority of PBL (92\%) remained in G0/G1. Hydroxyurea was added and the incubation continued for $20 \mathrm{~h}$ to allow cells to accumulate in $S$ phase. Less than $2 \%$ of cells escaped into $\mathrm{G} 2+\mathrm{M}$ phase. Following release of the hydroxyurea block there was a further increase in the proportion of cells in $S$ phase. Subsequent treatment three $h$ later with nocodazole resulted in arrest of cells in $\mathrm{M}$ phase. During the $21 \mathrm{~h}$ of treatment with nocodazole the proportion of $\mathrm{S}$ phase cells declined while an equivalent proportion of cells accumulated in $\mathrm{G} 2+\mathrm{M}$.

Phosphorylation of Op18 in relation to the cell cycle: To relate Op18 phosphorylation to transition of PBL through the cell cycle, PBL at different stages of the cell cycle shown in Figure 1, were labeled with ${ }^{32} \mathrm{P}_{\mathrm{i}}$ in the presence of the appropriate pharmacologic agent and phosphorylated Op18 was analyzed by 2-D gel electrophoresis. Freshly isolated quiescent (G0) PBL express low levels of Op18, however two phosphorylated forms, Op18a and Op18b, can be detected on 2-D gels of cells metabolically labeled with ${ }^{32} \mathrm{P}_{\mathrm{i}}$ using storage phosphor imaging (Fig. 2A). Within $5 \mathrm{~min}$ of stimulation of the TCR with OKT3, another form, Op18c, is prominently expressed and Op18a and Op18b are slightly increased (Fig. 2B). The $24 \mathrm{~h}$ OKT3 treated cells did not express Op18c and the amount of Op18a and Op18b increased slightly compared to the levels
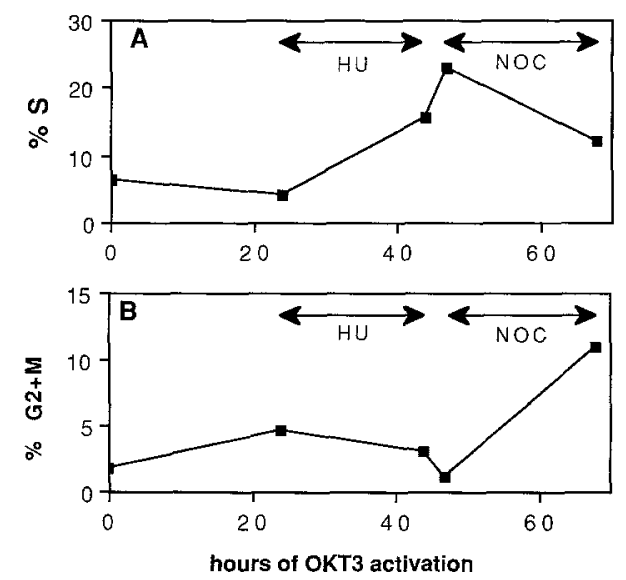

Figure 1. Cell cycle analysis of PBL by propidium iodide staining of DNA. The proportion of cells in various stages of the cell cycle was manipulated by sequential treatment of PBL with 10 $\mathrm{mM}$ hydroxyurea $(\mathrm{HU})$ and $100 \mathrm{ng} / \mathrm{ml}$ nocodazole (NOC) for the indicated times. DNA content of cells was determined by propidium iodide staining and FACS analysis. 

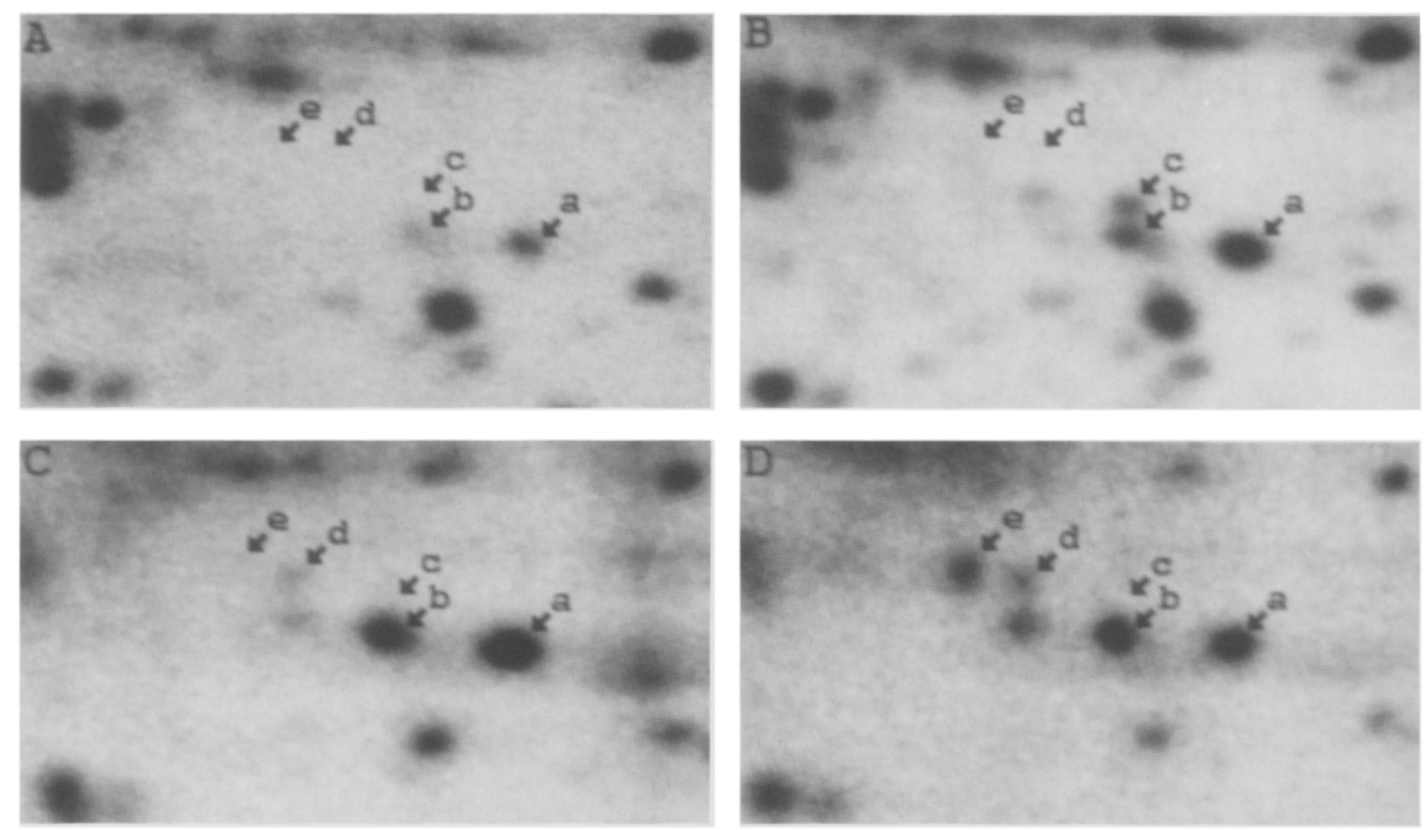

Figure 2. 2-D gel analysis of phosphorylated Op18 during the cell cycle. Freshly isolated PBL in G0 were labeled with ${ }^{32} \mathrm{P}_{\mathrm{i}}$ for $60 \mathrm{~min}$ and $\mathrm{Op} 18$ phosphorylated forms were analyzed by 2-D electrophoresis (Panel A). To obtain cells in the G0 to G1 transition, PBL were labeled as in panel A except that OKT3 was added during the last $5 \mathrm{~min}$. (Panel B). PBL arrested in $\mathrm{S}$ phase $(44 \mathrm{~h}$ of Fig. 1) were labeled in the presence of hydroxyurea (Panel C). PBL arrested in M phase ( $68 \mathrm{~h}$ of Fig.1) were labeled in the presence of nocodazole (Panel D). Phosphor storage screen exposure time in panels $A$ and $B$ is increased to permit clear visualization of Op18a and Op18b.

seen in Fig. 2B (data not shown). Analysis of PBL in S phase following $20 \mathrm{~h}$ of hydroxyurea treatment revealed a substantial increase in the amount of Op18a and Op18b whereas Op18c was still undetectable (Fig. 2C). Three h following removal of hydroxyurea, cells continued to enter $\mathrm{S}$ phase, however there was no significant change in Op18 phosphorylation (data not shown). Nocodazole was then added to the medium and the incubation continued. A significant number of cells entered $\mathrm{G} 2+\mathrm{M}$ by $21 \mathrm{~h}$ of nocodazole treatment (Fig. 1). At this time cells expressed phosphorylated Op18d and another phosphorylated polypeptide identified as Op18e (Fig. 2D), on the basis of Western blotting of PMA-activated Jurkat cells using anti-Op18. Again, Op18c could not be detected in cells arrested in $\mathrm{M}$ phase.

Inhibition of 0 p18 phosphorylation by calphostin C: In a previous study, we observed that the early phosphorylation producing Op18a, Op18b and Op18c in OKT3 stimulated PBL was inhibited by calphostin C, a specific inhibitor of protein kinase C, but not by HA1004, an inhibitor of cyclic nucleotide-dependent protein kinases (12). To determine the involvement of protein kinase $\mathrm{C}$ in Op18d and Op18e phosphorylation we examined phosphorylation patterns in Jurkat cells. Jurkat cells treated with OKT3 express all five of these phosphorylated forms of Op18 (Fig. $3 \mathrm{~A})$. When Jurkat cells were treated with calphostin $\mathrm{C}(1.26 \mu \mathrm{M})$ during the prelabeling period and were subsequently treated with OKT3 for $15 \mathrm{~min}$ there was a dramatic decrease in the extent of 

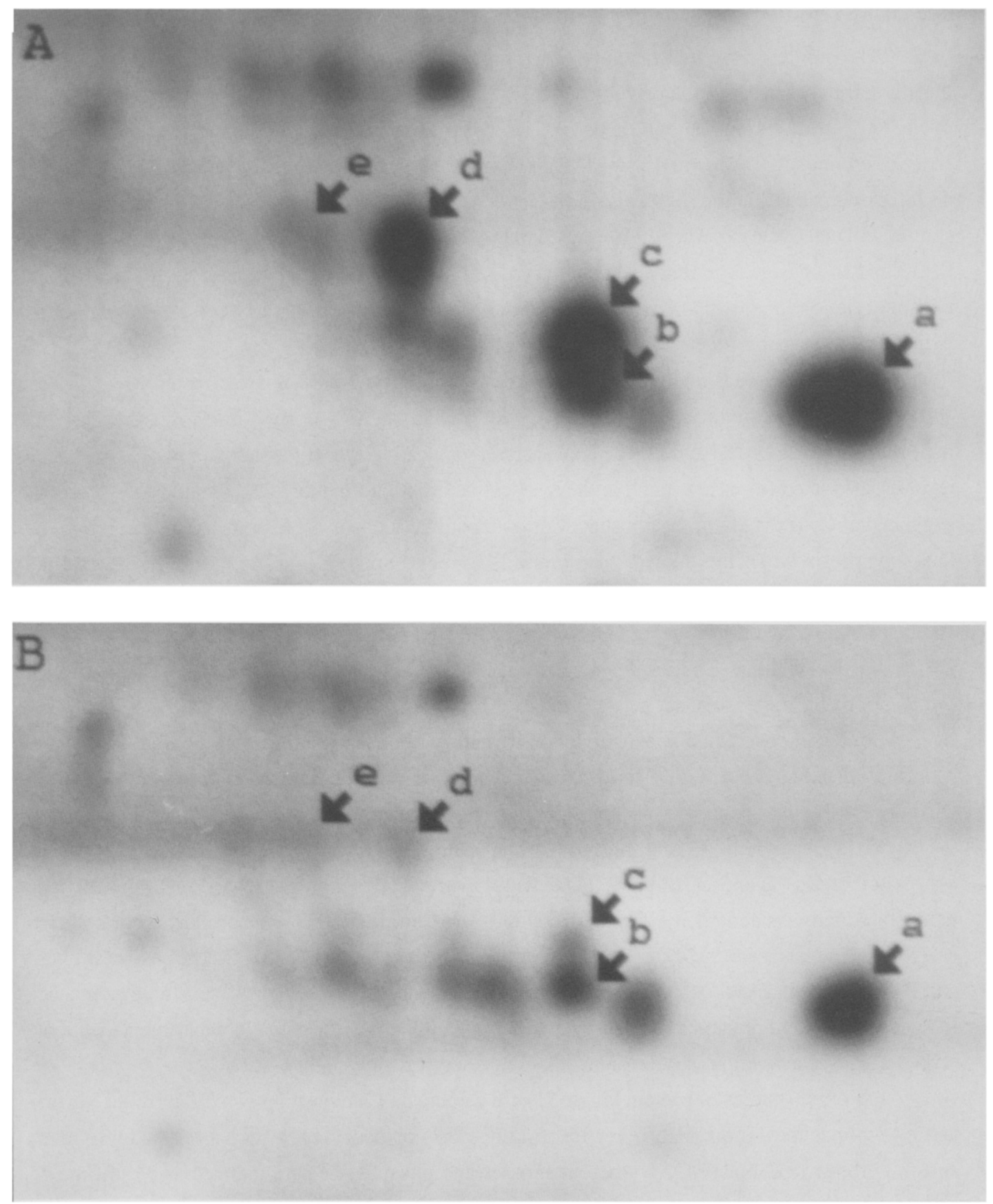

Figure 3. Inhibition of Op18 phosphorylation in Jurkat cells by calphostin C. Jurkat cells were labeled for 90 min with ${ }^{32} \mathrm{P}_{\mathrm{i}}$ without (Panel A) or with $1.26 \mu \mathrm{M}$ calphostin $\mathrm{C}$ (Panel B). OKT3 was added during the last 15 min.

Op18 phosphorylation (Fig. 3B). Phosphorylation of Op18c, Op18d and Op18e were virtually eliminated while levels of Op18a and Op18b were substantially reduced. Interestingly calphostin C treatment resulted in the appearance of a series of minor, more acidic phosphoproteins of similar MW as Op18a and Op18b. It is not known whether these phosphoproteins are related to Op18. 


\section{DISCUSSION}

The studies presented demonstrate changes in the pattern of phosphorylation of Op 18 during cell cycle progression. Whereas Op18a and Op18b were expressed throughout the cell cycle, Op18c was expressed only in early G1 and Op18d and Op18e were expressed in M phase, In asynchronous PBL activated with OKT3 we have observed the gradual loss of Op $18 \mathrm{c}$ by 24 to $48 \mathrm{~h}$ following stimulation. Expression of Op18c is not seen again until 48 to $72 \mathrm{~h}$ later (data not shown). In cell cycle experiments presented in this report we have not observed Op18c in late G1, $\mathrm{S}, \mathrm{G} 2$ and $\mathrm{M}$ phases. The reappearance of Op18c in asynchronous cells therefore likely reflects phosphorylation in cells that have completed the cell cycle and are in early G1, the stage during which Op18c was observed during transition from $\mathrm{G} 0$.

Phosphorylated forms Op18d and Op18e were observed in M phase-arrested PBL. Their appearance followed induction of new Op18 synthesis in late G1/S. By $3 \mathrm{~h}$ following release of the M phase block Op18d and Op18e levels decreased nearly 10 fold (data not shown). Op18 and its phosphorylated forms are found in the cytosol and are not found in isolated nuclei. Our results suggest that Op18d and Op18e phosphorylation most likely occurs in M following completion of DNA synthesis when the nuclear membrane is absent. Specific nuclear protein kinases and phosphatases induced during G2 and M phases may be accessable to the cytoplasmic compartment and be capable of phosphorylating Op18 or regulating cytoplasmic protein kinases responsible for Op18 phosphorylation. The results suggest that Op18d and Op18e may be involved in mitotic events prior to chromosomal segregation and cell division.

Prior studies of Op18 phosphorylation in human T cells have utilized asynchronous rapidly proliferating cells $(2,9-11,13)$. Two phosphorylated polypeptides corresponding to Op18c and Op18d were found to be rapidly phosphorylated in response to TCR-CD3 activation in Jurkat cells, $(9,13) \mathrm{IL}-2$ dependent PBL cultures (19) and a normal CD4 ${ }^{+} \mathrm{T}$ cell line P28D (20). The expression of Op18c and Op18d in P28D cells was variable depending on the signal transduction pathway which was activated (20). Expression of Op18c may reflect that proportion of cells in early G1. The basis for the differential effect on rapid phosphorylation of Op18d in T cell lines and $\mathrm{IL}-2$ dependent $\mathrm{T}$ cell cultures compared to freshly isolated synchronized $\mathrm{T}$ cells may be related to levels of different precursor phosphorylated forms or to their cytoplasmic compartmentalization, or to the state of activation of other signaling molecules or pathways.

Inhibition studies of protein kinase $\mathrm{C}$ with calphostin $\mathrm{C}$ suggest involvement of this kinase in Op18 phosphorylation. However the findings do not necessarily indicate that Op18 is a substrate for protein kinase $\mathrm{C}$. Numerous kinases and phosphatases are induced as part of the $\mathrm{T}$ cell activation cascade whose activities may be regulated in part by protein kinase $C$. The occurrence of phosphorylated forms of Op18 that differ in isoelectric points is likely the result of phosphorylation at a variable number of sites. The more acidic forms presumably are phosphorylated at a greater number of residues. However other post-translational modifications resulting in increased net negative charge may also be partially responsible for Op18 heterogeneity. Identification of Op18 phosphorylation sites in the different phosphorylation forms will substantially contribute to elucidation of precursor/product relationships in Op18 phosphorylation and their potential role in cell proliferation. 
Acknowledgment: This work was supported in part by NIH grant CA26803.

\section{REFERENCES}

(1) Hanash, S. M., Strahler, J. R., Kuick, R., Chu, E. H. Y. and Nichols, D. (1988) J. Biol. Chem. 263, 12813-12815.

(2) Melhem, R. F., Zhu, X. X., Hailat, N., Strahler, J. and Hanash, S. M. (1991) J. Biol. Chem. 266, 17747-17753.

(3) Cooper, H. L., McDuffie, E. and Braverman, R. (1989) J. Immunol. 143, 956-963.

(4) Zhu, X. X., Kozarsky, K., Strahler, J. R., Eckerskorn, C., Lottspeich, F., Melhem, R., Lowe, J., Fox, D. A., Hanash, S. M. and Atweh, G. F. (1989) J. Biol. Chem. 264, 1455614560 .

(5) Melhem, R. F., Strahler, J. R., Hailat, N., Zhu, X. X. and Hanash, S. M. (1991) Biochem. Biophsy. Res. Commun. 179, 1649-1655.

(6) Doye, V., Boutterin, M. C. and Sobel, A. (1990) J. Biol. Chem. 265, 11650-11655.

(7) Schubart, U. K., Banerjee, M. D. and Eng, J. (1989) Eur. J. DNA 8, 389-398.

(8) Gullberg, M., Noreus, K., Brattsand, G., Friedrich, B. and Shingler, V. (1990) J. Biol. Chem. 265, 17499-17505.

(9) Peyron, J.-F., Aussel, C., Ferrua, B., Haring, H. and Fehlmann, M. (1989) Biochem. J. 258, 505-510.

(10) Hailat, N., Strahler, J., Melhem, R., Zhu, X. X., Brodeur, G., Seeger, R. C., Reynolds, C. P. and Hanash, S. M. (1990) Oncogene 5, 1615-1618.

(11) Sobel, A., Boutterin, M. C., Beretta, L., Chneiweiss, H., Doye, V. and Peyro-Saint-Paul, H. (1989) J. Biol. Chem. 264, 3765-3772.

(12) Strahler, J. R., Hailat, N., Lamb, B. J., Rogers, K. P., Underhill, J. A., Melhem, R. F., Keim, D. R., Zhu, X. X., Kuick, R. D., Fox, D. A. and Hanash, S. M. (Submitted).

(13) Mary, D., Peyron, J.-F., Auberger, P., Aussel, C. and Fehlmann, M. (1989) J. Biol. Chem. 264, 14498-14502.

(14) Cooper, H. L., Fuldner, R., McDuffie, E. and Braverman, R. (1990) J. Immunol. 145, $1205-1213$.

(15) Miller-Faures, A., Michel, N., Aguilera, A., Blave, A. and Miller, A. O. A. (1981) Cell Tissue Kinet 14, 501-514.

(16) Brun, R. F., Miller, F. D., Merriman, R. L., Howbert, J. J., Heath, W. F., Kobayashi, E., Takahashi, I., Tamaoki, T. and Nakano, H. (1991) Biochem. Biophys. Res. Commun. 176, 288-293.

(17) Strahler, J. R., Kuick, R. and Hanash, S. M. (1989) Protein Structure: A Practical Approach (T. Creighton), , pp. 65-92. IRL Press Ltd., Oxford.

(18) Johnston, R. F., Pickett, S. C. and Barker, D. L. (1990) Electrophoresis 11, 355-360.

(19) Cooper, H. L., Fuldner, R., McDuffie, E. and Braverman, R. (1991) J. Immunol. 146, 3689-3696.

(20) le Gouvello, S., Chneiweiss, H., Tarantino, N., Debre, P. and Sobel, A. (1991) FEBS Letter 287, 80-84. 